\title{
Regorafenib treatment for advanced, refractory gastrointestinal stromal tumor: a report of the UK managed access program
}

\author{
Attila Kollàr ${ }^{{ }^{*}}$, Marco Maruzzo², Christina Messiou², Elisabeth Cartwright ${ }^{2}$, Aisha Miah², Juan Martin-Liberal²,

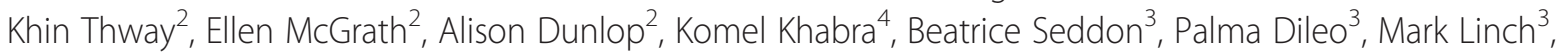 \\ lan Judson ${ }^{2}$ and Charlotte Benson ${ }^{2}$
}

\begin{abstract}
Background: Tyrosine kinase inhibitors (TKI) have revolutionized the treatment of gastrointestinal stromal tumors (GIST) although most patients develop resistance to first and second-line therapies. Regorafenib, an oral multi-targeted TKI, has demonstrated benefit in previously treated GIST patients.

Methods: We assessed safety and activity of regorafenib in patients treated within the Managed Access Program (MAP). All consecutive patients with advanced GIST who had progressed on or were intolerant to imatinib and sunitinib were recruited from the Royal Marsden and University College Hospitals. We retrospectively reviewed the data for response, toxicity, treatment duration and survival. Response was assessed by RECIST and Choi criteria. Toxicity was graded according to CTCAE v4.0 criteria.

Results: 20 patients were included in the MAP in the UK between 3/2013 and 9/2013. Median age was 68 (range 45-87), 65\% of patients were male. Performance Status was 0-1 for 18 patients (90\%), 2 for 2 patients (10\%). The median treatment duration was 9.25 months (range 0.1-15.33). 18 patients were assessable for response and all patients attained a best response of at least stable disease. At a median follow-up of 12.6 months, there were 2 partial responses (11\%) by RECIST and 7 partial responses (39\%) according to Choi criteria. 7 patients remain on regorafenib. 3 patients discontinued treatment due to unacceptable adverse events; fistulation, myalgia and fatigue. 10 (50\%) patients had grade 3 toxicities and 11 (55\%) patients required a dose reduction. Median PFS was 9.4 months ( $95 \%$ Cl: 6.2-not calculable) and median OS was 12.2 months ( $95 \%$ Cl: 10.5 -not calculable). Notably, prolonged stable disease was seen in 1 patient with exon 9 mutation and 1 patient with PDGFR D842V mutation.

Conclusions: These data demonstrate encouraging activity and tolerability of regorafenib in routine clinical practice. The documented adverse events are in line with previous trial data.
\end{abstract}

Keywords: Gastrointestinal stromal tumor, Regorafenib, Mutation, Choi

\section{Background}

Gastrointestinal stromal tumors (GIST) are the most common mesenchymal neoplasm in the gastrointestinal tract with a worldwide incidence of approximately 15 cases per million per year [1-3]. GIST are thought to be derived from the interstitial cells of Cajal that coordinate the peristaltic action of the gastrointestinal tract [4]. In localized

\footnotetext{
* Correspondence: attila.kollar@insel.ch

'Department of Medical Oncology, University Hospital Bern, Inselspital, 3010 Bern, Switzerland

Full list of author information is available at the end of the article
}

disease, the primary treatment modality is surgery but despite complete resection, disease recurrence or metastasis occurs in more than $40 \%$ of patients [3]. In this advanced disease setting, cytotoxic chemotherapy has been largely ineffective [5,6] however, molecular characterization of GIST has transformed the therapeutic landscape [7]. The majority of GIST have activating mutations in the genes for stem cell factor receptor (KIT, 85\%) or platelet derived growth factor receptor $\alpha$ (PDGFRA, approximately 6-8\%) and more rarely exclusive mutations in BRAF, NF1 and succinate dehydrogenase are found [2,8-12]. Introduction 
of imatinib, a small molecule inhibitor of KIT and PDGFR $\alpha$ has had a major impact in this disease and is the standard $1^{\text {st }}$ line therapy [13]. Sunitinib, a multikinase inhibitor, is approved as second line therapy after disease progression during imatinib or for patients that are imatinib-intolerant [14].

Recently, regorafenib was introduced as a novel, oral multikinase inhibitor whose effects are achieved by targeting angiogenic (VEGFR1-3 and TEK), stromal (PDGFR and FGFR) and oncogenic (KIT, RET, RAF1, BRAF) receptor tyrosine kinases [15-18]. Preclinical data has shown that regorafenib has antitumor activity against human GIST xenografts [19].

Following a phase I trial, which led to the recommended dosing schedule of $160 \mathrm{mg}$ OD 3 weeks on and 1 week off, George and colleagues published the results of the multicentre phase II trial investigating the role of regorafenib in metastatic and/or unresectable GIST with progression on or intolerance to imatinib and prior failure of sunitinib. $12 \%(4 / 33)$ of the patients achieved a partial response (PR) per RECIST 1.1. and 66\% (22/33) experienced stable disease (SD) for longer than 16 weeks. Median progressionfree survival was 10.0 months [20,21].

Based on these promising results an international randomized, double-blind, placebo-controlled phase III trial (GRID) was conducted. 199 patients with metastatic or unresectable GIST were randomized to receive $160 \mathrm{mg}$ of regorafenib or placebo, after failure of imatinib and sunitinib. The median PFS was 4.8 months for regorafenib vs 0.9 months for placebo. Overall survival at the cutoff time was similar in both study arms, $22 \%$ events in the regorafenib and $26 \%$ in the placebo group, respectively. The median daily drug dose was $146.8 \mathrm{mg}$. The two most commonly reported drug-related adverse events were hand-foot-syndrome and hypertension [22].

Here we describe the safety and efficacy of regorafenib in patients enrolled in a managed access program (MAP), which was offered after the results of the GRID trial have been published and before the commercial launch. The MAP provided an opportunity to assess regorafenib in a cohort of advanced GIST patients in a routine clinical setting who had no other approved therapeutic options.

\section{Methods}

\section{Study design and population}

The inclusion criteria were in the main in accordance with the GRID trial [22]. In short, patients were eligible if they were at least 18 years of age with histologically confirmed metastatic and/or unresectable GIST, had progressed on or were intolerant of imatinib and/or sunitinib, had a performance status of $0-2$ and had adequate haematological, liver and renal function. Relevant exclusion criteria included uncontrolled hypertension and any illness or medical condition that was unstable or could jeopardize the safety of the patient and his/her compliance in the program.

We reviewed the data of all the consecutive patients recruited into the MAP at the Royal Marsden and University College London Hospitals. Patients' data were prospectively collected in the hospital electronic patient records systems. Local institutional ethical approvals were obtained.

\section{Treatment}

All patients gave informed consent for treatment. Regorafenib was started at the full dose of $160 \mathrm{mg}$ orally once daily for the first 3 weeks of each 4 week cycle. Initial dose reductions were permitted depending on PS and/or comorbidities according to the treating clinician's discretion. Patients were treated continuously until disease progression or unacceptable toxicities. Dose reductions were implemented for moderate or severe toxicity. During the MAP period, regorafenib was provided by Bayer plc.

\section{Assessments}

Tumor assessments were conducted with repeated computer tomography $(\mathrm{CT})$ scan and or magnetic resonance imaging (MRI) at baseline and subsequently after every 2 cycles of treatment. Radiologic responses were assessed according to RECIST 1.1 criteria [23] and Choi criteria [24] by a single specialist Sarcoma Radiologist (C.M.).

Adverse events were monitored in all patients who received regorafenib and graded according to the Common Terminology Criteria for Adverse Events (CTCAE) version 4. All adverse events were recorded from the first intake of regorafenib until treatment discontinuation.

\section{Statistical analysis}

Patient and disease characteristics were analysed using descriptive statistics. Overall survival (OS) was defined from date of starting treatment to date of death. Any surviving patients were censored at last follow up. Progression free survival (PFS) was defined from date of starting treatment to date of progression, assessed by RECIST 1.1., or death. Any progression free surviving patients were censored at last follow up. PFS and OS were estimated using Kaplan-Meier analysis. Median follow up was calculated using the inverse Kaplan Meier method and the median rates and 6 month rates are presented along with the 95\% Confidence Intervals (CI).

\section{Results}

Patient characteristics

Between March and September 2013, 20 consecutive patients with a diagnosis of metastatic GIST were included in the MAP. Baseline characteristics are provided in Table 1. Median age was 68 years (range 45-87). 13 (65\%) were male and 7 (35\%) female. Most patients had an 


\section{Table 1 Patient characteristics}

\begin{tabular}{lc}
\hline Total & $\mathbf{2 0}$ \\
Age (median, range) & $\mathbf{6 8}(\mathbf{4 5 - 8 7 )}$ \\
\hline Sex & $\mathbf{n ~ ( \% )}$ \\
$\quad$ Male & $13(65 \%)$ \\
$\quad$ Female & $7(35 \%)$ \\
ECOG performance status at baseline & \\
$0-1$ & $18(90 \%)$ \\
2 & $2(10 \%)$ \\
Site of primary & \\
Gastric & $8(40 \%)$ \\
Non-gastric & $12(60 \%)$ \\
Previous treatment lines & \\
2 & $16(80 \%)$ \\
3 & $4(20 \%)$ \\
Mutational analysis & \\
KIT exon 11 mutation & $12(60 \%)$ \\
KIT exon 9 mutation & $1(5 \%)$ \\
PDGFR D842V mutation & $1(5 \%)$ \\
Not avalilable & $6(30 \%)$ \\
\hline
\end{tabular}

Eastern Cooperative Oncology Group (ECOG) PS of 0 or 1 , with 2 patients $(10 \%)$ having a PS of 2 . All the patients had documented radiological progressive disease within three months prior to starting on regorafenib. GIST was of gastric origin in $8(40 \%)$ patients. The remaining patients had GIST originating from small bowel, retroperitoneal, esophagogastric and one pelvic/rectal origin. Mutational analysis was available for 14 patients, with a majority of exon 11 mutations (60\%); one patient had a mutation in the exon $9(5 \%)$ and another one had a PDGFRA D842V mutation (5\%). All the patients received prior treatment with imatinib and sunitinib. Median time on imatinib and sunitinib treatment was 37 months (range 2-87) and 11 months (range 2-46), respectively. Four patients $(20 \%)$ received another line of treatment before regorafenib was initiated; 3 of them in a phase I setting and one patient received nilotinib. Median year of first diagnosis of GIST was 2006 (range 2000-2012). 5 patients received post-study treatment; four with imatinib alone or with a phase I investigational agent and one patient radiotherapy.

\section{Dosing and toxicity}

The median treatment duration was 9.25 months (range 0.1-15.33). 15 (75\%) patients started at the full dose of $160 \mathrm{mg}$. Starting dose was lower in 5 patients due to PS, age and persisting toxicity from previous treatment; 3 patients started at $120 \mathrm{mg}(15 \%)$ and 2 at $80 \mathrm{mg}(10 \%)$ of regorafenib. 11 (55\%) and $2(10 \%)$ patients received dose modification during the treatment, with dose reduction or escalation, respectively. 3 patients (15\%) discontinued treatment during the first month of treatment. One patient experienced an exacerbation of a known fistula, one suffered from severe pelvic pain and one from increasing fatigue. In all patients, drug-related adverse events of any grade were reported. The most common adverse events of any grade were fatigue in $16(80 \%)$ patients, hand-foot-skin reaction in 11 (55\%) patients and hypertension and diarrhea in half of the patients. Laboratory abnormalities of any grade were documented in 2 patients in terms of elevated alkaline phosphatase and hyperbilirubinemia. Grade 3 toxicities were documented in 10 patients (50\%). 3 patients (15\%) each experienced hand-foot-skin reaction and hypertension, respectively, 2 (10\%) patients reported skin rash, 1 patient $(5 \%)$ had fatigue, one patient $(5 \%)$ had oral mucositis and in one patient a hyperbilirubinemia was reported. No grade 4 toxicities or toxic deaths were reported. Toxicities are summarized in Table 2.

\section{Efficacy}

After a median follow-up of 12.6 months, $18 / 20$ patients were assessable for response according to RECIST and Choi criteria. Two patients were not assessable because of early discontinuation before radiological assessment. All assessable patients attained a best response of at least stable disease. Two partial responses (11\%) were documented according to RECIST. In comparison, assessment by Choi criteria revealed a partial response in 7 patients (39\%). An example of radiological response by Choi is illustrated in Figure 1. Notably, in the 4 patients that gained an improvement in PS, there was at least SD by both RECIST (2 PR, 2 SD) and Choi (3 PR, 1 SD) criteria. At the time of analysis (14.06.2014), 13 (65\%) patients had discontinued regorafenib and 7 (35\%) patients were still benefiting from regorafenib treatment. The

Table 2 Toxicity - number of patients/proportion out of all 20 patients

\begin{tabular}{lcc}
\hline Toxicity & All grades & Grade 3-4 \\
\hline Fatigue & $16(80 \%)$ & $1(5 \%)$ \\
Hand-foot-syndrome & $11(55 \%)$ & $3(15 \%)$ \\
Hypertension & $10(50 \%)$ & $3(15 \%)$ \\
Diarrhoea & $10(50 \%)$ & - \\
Oral mucositis & $8(40 \%)$ & $1(5 \%)$ \\
Hoarseness & $8(40 \%)$ & - \\
Constipation & $7(35 \%)$ & - \\
Rash, maculopapular & $6(30 \%)$ & $2(10 \%)$ \\
Anorexia & $5(25 \%)$ & - \\
Nausea & $4(20 \%)$ & - \\
Hepatobiliary toxicity & $2(10 \%)$ & $1(5 \%)$ \\
\hline
\end{tabular}




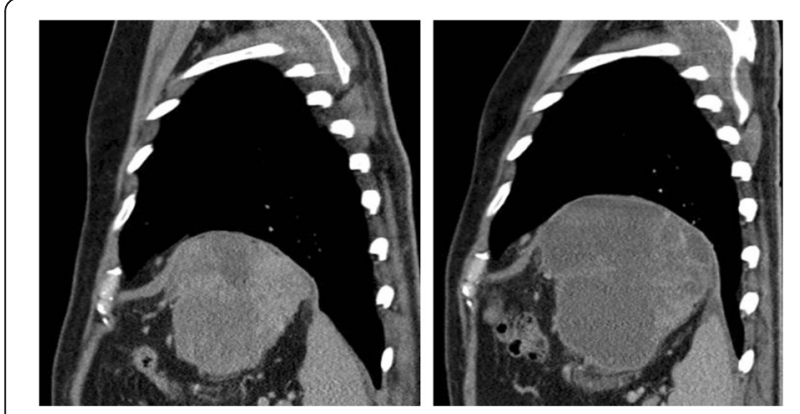

Figure 1 Sagittal CT image of left upper quadrant mass. Although the mass has increased in size, the drop in Hounsfield units from 39 to 16 suggests partial response by Choi criteria.

median PFS was 9.4 months (95\% Cl: 6.2-not calculable) and the 6-month PFS was $80.0 \%$ (95\% CI 55.1-92.0) (Figure 2). The median OS was 12.2 months $(95 \% \mathrm{Cl}$ : 10.5-not calculable) and the 6-month OS rate was 89.7\% (95\% CI 64.8-97.3) (Figure 3).

\section{Discussion}

Regorafenib is a multi-targeted tyrosine kinase inhibitor with evidence of non-cross resistant activity in patients with previously treated GIST. The phase III clinical trial of regorafenib in GIST demonstrated a statistically significant improved progression free survival in the third line setting for patients with GIST following failure of imatinib and sunitinib [22]. Its broad spectrum targeting pathways involved in oncogenesis have made this drug very appealing. In the MAP, patients with no other therapeutic options had the opportunity to benefit from regorafenib. We were able to assess efficacy and safety of regorafenib treatment in a routine clinical practice setting at two separate sarcoma centers in the UK.

Median treatment duration of regorafenib in the GRID trial was reported to be 22.9 weeks which is approximately

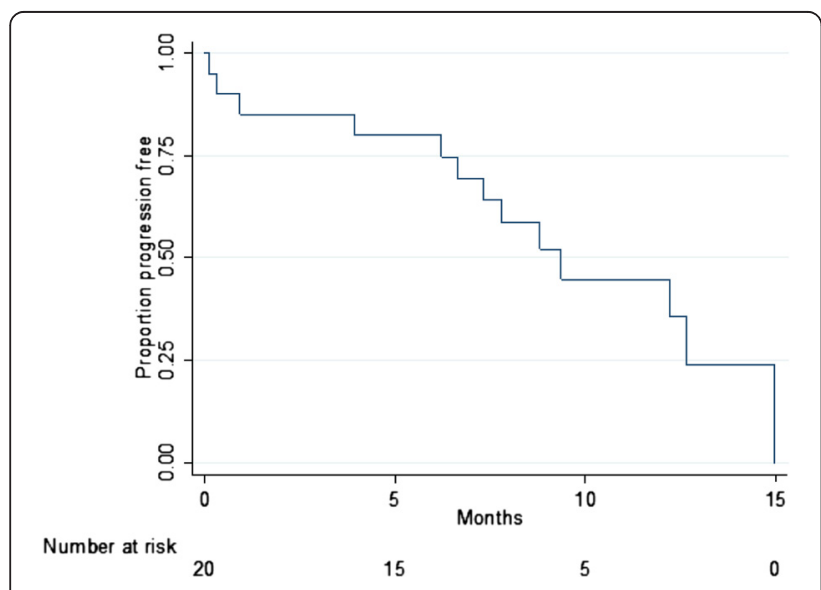

Figure 2 Median PFS: 9.4 months (95\% Cl: 6.2 - not calculable).

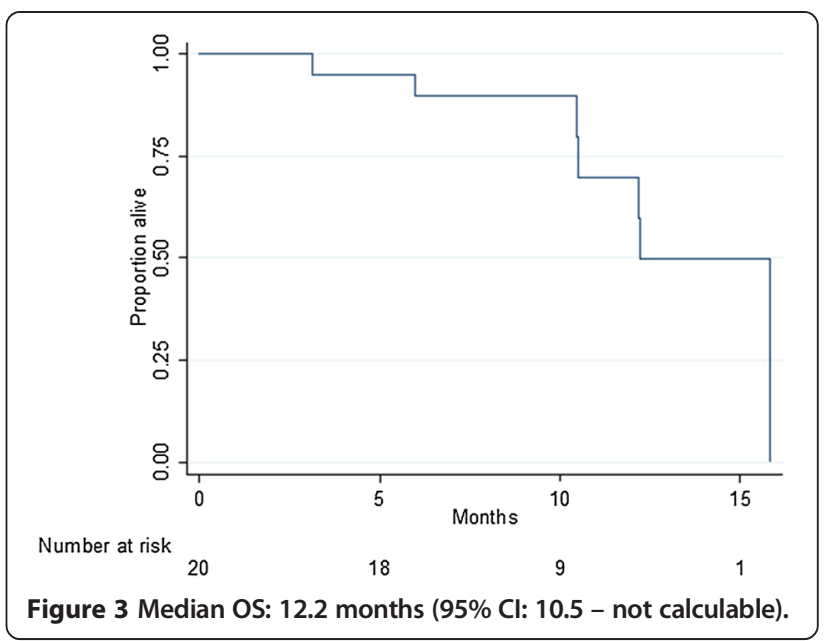

3 months less than in our cohort. According to the blinded central review and the investigator based assessment median PFS in the phase III trial was 4.9 months and 7.4 months, respectively, with a PFS at 6 months of $60 \%$, also less than in our analysis. However these differences cannot be meaningfully compared due to our smaller patient numbers and less rigorous inclusion and stopping criteria. Interestingly a larger number of patients received more than 2 previous treatment lines in the GRID trial that could also account for such a difference. Complete radiological responses were not seen in either the GRID trial, or in the MAP. Twice as many partial responses were documented by RECIST criteria in our cohort in comparison with the trial setting, $11 \%$ and $4.5 \%$, respectively. Additionally, we assessed response according to the Choi criteria taking into account the specific radiological changes of GIST during TKI therapy. As expected, the partial response rate according to Choi criteria was increased compared with RECIST 1.1. Shinagare and colleagues reported recently on the correlation of different assessment techniques with the outcome. Whereas PR was more frequent by Choi (90\%) than RECIST 1.1, disease control rate was similar between the different tumor response criteria. Interestingly, the concordance of RECIST 1.1 evaluation with PFS and OS was more exact than with Choi [25]. Our data confirm that regorafenib has the potential to control disease over many months. There were not enough patients to make a fair comparison between the two assessment criteria. However, the correlation between PS improvement and response was higher when using response evaluation by Choi criteria.

Notably, we included one patient with an exon 9 and one with a PDGFRA D842V mutation. Both patients experienced prolonged stable disease for 8 and 12 months, respectively. A PR by Choi criteria was documented in the PDGFRA mutated case. In five patients with primary resistance to sunitinib, disease stabilization and even 
partial responses by Choi and RECIST criteria were documented on regorafenib treatment suggesting non-cross resistance of these agents. These findings support the strategy that is currently being tested of alternating sunitinib and regorafenib in an attempt to try and overcome acquired resistance mutations (NCT02164240).

All patients treated within the MAP experienced mild adverse events. The documented toxicities, particularly of grade 3, are consistent with previous published data. Fatigue, hoarseness, constipation and rash were more often reported in our cohort than in the GRID trial, but are similar to other published regorafenib studies [8,20,21,26-28]. The need to reduce the standard treatment dose of $160 \mathrm{mg}$ in more than half of the patients (55\%) suggest that the optimal dose of regorafenib may be less than $160 \mathrm{mg}$. Patients that received $120 \mathrm{mg}$ once daily rarely suffered with $\geq$ grade 3 toxicities. The median daily dose of regorafenib in the GRID trial was reported to be $146.8 \mathrm{mg}$ in concordance with our observation. Notably, our experience supports the perception that the majority of adverse events are reversible and manageable with dose delays, dose reductions and intensified supportive care [29]. We performed clinical and laboratory assessment of adverse events every two weeks during the first 3 cycles. Specialist nursing input was available for patients receiving regorafenib, helping to raise patient awareness of expected side-effects and advise on toxicity management in a timely fashion. We feel that these intensive early assessments coupled with the nursing support plays a crucial part in successful management regorafenib therapy.

Importantly for a trial of a palliative therapy, the GRID study included quality of life outcomes, albeit only as exploratory endpoints. Poole and colleagues reported the QoL data from assessments of global health status and the physical functioning domain scores and demonstated no statistical differences between the regorafenib and placebo cohorts highlighting that regorafenib treatment toxicities do not have a negative impact on QoL [30]. In our study, formal QoL assessment was not performed but PS was rigorously documented. Four out of 20 patients (20\%) had improved their general status consistent with the results seen in the GRID trial. This observation that regorafenib is a well-tolerated treatment that leads to symptomatic benefit in a sizeable proportion of patients in this study strengthens the role of regorafenib in routine clinical practice. Furthermore, the fact that patients with a PS of 2 were included in the MAP and that their adverse events were successfully managed makes regorafenib treatment feasible in a real world population. We feel that this toxicity management should include close observation and consideration of a reduced initial dose of regorafenib in patients who are PS 2 or who have suffered with previous TKI toxicity. According to the known phase III trials (CORRECT and GRID) there seems to be no worsening of regorafenib toxicity following treatment with other tyrosine kinase inhibitors like imatinib or sunitinib [22,28].

\section{Conclusions}

In conclusion, our data confirms the efficacy and safety data of the GRID trial supporting the use of regorafenib in a real world setting including a range of differing mutational subtypes. Additional data regarding the efficacy of regorafenib in relation to the mutational status is needed.

\section{Abbreviations \\ UK: United Kingdom; EMEA: European medicines agency; MAP: Managed access program; GIST: Gastrointestinal stromal tumor; TKI: Tyrosine kinase inhibitor; PDGFRA: Platelet-derived growth factor receptor a; CT: Computer tomography scan; MRI: Magnetic resonance imaging; CTCAE: Common terminology criteria for adverse events; RECIST: Response evaluation criteria in solid tumors; ECOG: Eastern cooperative oncology group; PS: Performance score; OS: Overall survival; PFS: Progression-free survival; Cl: Confidence interval; PR: Partial response; SD: Stable disease; QoL: Quality of life.}

\section{Competing interests}

Kollàr Attila: Advisory Board for Bayer Marco Maruzzo: none.

M.L., A.M., I.J. and C.B. have all received research support from AstraZeneca, Bayer, GlaxoSmithKline, Eisai, Novartis, Ziopharm Oncology.

\section{Authors' contributions}

KK performed the statistical analysis. All authors approved the final manuscript.

\section{Acknowledgments}

We acknowledge support from the NIHR Royal Marsden/ICR Biomedical Research Centre.

\section{Author details}

${ }^{1}$ Department of Medical Oncology, University Hospital Bern, Inselspital, 3010 Bern, Switzerland. ${ }^{2}$ Sarcoma Unit, Royal Marsden NHS Foundation Trust, Fulham Road, SW3 6JJ London, UK. ${ }^{3}$ University College London Hospitals NHS Foundation Trust, Euston Road, NW1 2BU London, UK. ${ }^{4}$ Research Data Management and Statistics Unit (RDSU), The Royal Marsden NHS Foundation Trust, London, UK.

Received: 18 November 2014 Accepted: 25 November 2014

Published: 4 December 2014

\section{References}

1. Gatta G, van der Zwan JM, Casali PG, Siesling S, Dei Tos AP, Kunkler I, Otter R, Licitra L, Mallone S, Tavilla A, Trama A, Capocaccia R, RARECARE working group: Rare cancers are not so rare: the rare cancer burden in Europe. Eur J Cancer 2011, 47(17):2493-511.

2. Demetri GD, Mehren M, Antonescu CR, DeMatteo RP, Ganjoo KN, Maki RG, Pisters PW, Raut CP, Riedel RF, Schuetze S, Sundar HM, Trent JC, Wayne JD: NCCN Task Force report: update on the management of patients with gastrointestinal stromal tumors. J Natl Compr Canc Netw 2010, 8(Suppl 2):S1-41. quiz S42-4.

3. Joensuu H: Adjuvant treatment of GIST: patient selection and treatment strategies. Nat Rev Clin Oncol 2012, 9(6):351-8

4. Sircar K, Hewlett BR, Huizinga JD, Chorneyko K, Berezin I, Riddell RH: Interstitial cells of Cajal as precursors of gastrointestinal stromal tumors. Am J Surg Pathol 1999, 23(4):377-89.

5. Edmonson JH, Marks RS, Buckner JC, Mahoney MR: Contrast of response to dacarbazine, mitomycin, doxorubicin, and cisplatin (DMAP) plus GM-CSF between patients with advanced malignant gastrointestinal stromal tumors and patients with other advanced leiomyosarcomas. Cancer Invest 2002, 20(5-6):605-12. 
6. Dematteo RP, Heinrich MC, El-Rifai WM, Demetri G: Clinical management of gastrointestinal stromal tumors: before and after STI-571. Hum Pathol 2002, 33(5):466-77

7. Caram MV, Schuetze SM: Advanced or metastatic gastrointestinal stromal tumors: systemic treatment options. J Surg Oncol 2011, 104(8):888-95.

8. Heinrich MC, Corless CL, Demetri GD, Blanke CD, von Mehren M, Joensuu $H_{\text {, }}$ McGreevey LS, Chen CJ, Van den Abbeele AD, Druker BJ, Kiese B, Eisenberg B, Roberts PJ, Singer S, Fletcher CD, Silberman S, Dimitrijevic S, Fletcher JA: Kinase mutations and imatinib response in patients with metastatic gastrointestinal stromal tumor. J Clin Oncol 2003, 21(23):4342-9.

9. Hirota S, Isozaki K, Moriyama Y, Hashimoto K, Nishida T, Ishiguro S, Kawano K, Hanada M, Kurata A, Takeda M, Muhammad Tunio G, Matsuzawa Y, Kanakura Y, Shinomura Y, Kitamura Y: Gain-of-function mutations of c-kit in human gastrointestinal stromal tumors. Science 1998, 279(5350):577-80.

10. Heinrich MC, Corless CL, Duensing A, McGreevey L, Chen CJ, Joseph N, Singer S, Griffith DJ, Haley A, Town A, Demetri GD, Fletcher CD, Fletcher JA: PDGFRA activating mutations in gastrointestinal stromal tumors. Science 2003, 299(5607):708-10

11. Janeway KA, Kim SY, Lodish M, Nosé V, Rustin P, Gaal J, Dahia PL, Liegl B, Ball ER, Raygada M, Lai AH, Kelly L, Hornick JL, Pediatric NIH, Wild-Type GIST C, O'Sullivan M, de Krijger RR, Dinjens WN, Demetri GD, Antonescu CR, Fletcher JA, Helman L, Stratakis CA: Defects in succinate dehydrogenase in gastrointestinal stromal tumors lacking KIT and PDGFRA mutations. Proc Natl Acad Sci U S A 2011, 108(1):314-8.

12. Corless CL, Barnett CM, Heinrich MC: Gastrointestinal stromal tumours: origin and molecular oncology. Nat Rev Cancer 2011, 11(12):865-78.

13. Demetri $G D$, von Mehren $M$, Blanke $C D$, Van den Abbeele AD, Eisenberg $B$, Roberts PJ, Heinrich MC, Tuveson DA, Singer S, Janicek M, Fletcher JA, Silverman SG, Silberman SL, Capdeville R, Kiese B, Peng B, Dimitrijevic S, Druker BJ, Corless C, Fletcher CD, Joensuu H: Efficacy and safety of imatinib mesylate in advanced gastrointestinal stromal tumors. $N$ Engl J Med 2002, 347(7):472-80.

14. Demetri GD, van Oosterom AT, Garrett CR, Blackstein ME, Shah MH, Verweij J, McArthur G, Judson IR, Heinrich MC, Morgan JA, Desai J, Fletcher CD, George S, Bello CL, Huang X, Baum CM, Casali PG: Efficacy and safety of sunitinib in patients with advanced gastrointestinal stromal tumour after failure of imatinib: a randomised controlled trial. Lancet 2006, 368(9544):1329-38.

15. Abrams TJ, Lee LB, Murray LJ, Pryer NK, Cherrington JM: SU11248 inhibits KIT and platelet-derived growth factor receptor beta in preclinical models of human small cell lung cancer. Mol Cancer Ther 2003, 2(5):471-8.

16. Mendel DB, Laird AD, Xin X, Louie SG, Christensen JG, Li G, Schreck RE, Abrams TJ, Ngai TJ, Lee LB, Murray $\sqcup$, Carver J, Chan E, Moss KG, Haznedar JO, Sukbuntherng J, Blake RA, Sun L, Tang C, Miller T, Shirazian S, McMahon G, Cherrington JM: In vivo antitumor activity of SU11248, a novel tyrosine kinase inhibitor targeting vascular endothelial growth factor and plateletderived growth factor receptors: determination of a pharmacokinetic/ pharmacodynamic relationship. Clin Cancer Res 2003, 9(1):327-37.

17. O'Farrell AM, Abrams TJ, Yuen HA, Ngai TJ, Louie SG, Yee KW, Wong LM, Hong W, Lee LB, Town A, Smolich BD, Manning WC, Murray LJ, Heinrich MC, Cherrington JM: SU11248 is a novel FLT3 tyrosine kinase inhibitor with potent activity in vitro and in vivo. Blood 2003, 101(9):3597-605

18. Osusky KL, Hallahan DE, Fu A, Ye F, Shyr Y, Geng L: The receptor tyrosine kinase inhibitor SU11248 impedes endothelial cell migration, tubule formation, and blood vessel formation in vivo, but has little effect on existing tumor vessels. Angiogenesis 2004, 7(3):225-33.

19. Wilhelm SM, Dumas J, Adnane L, Lynch M, Carter CA, Schütz G, Thierauch $\mathrm{KH}$, Zopf D: Regorafenib (BAY 73-4506): a new oral multikinase inhibitor of angiogenic, stromal and oncogenic receptor tyrosine kinases with potent preclinical antitumor activity. Int J Cancer 2011, 129(1):245-55.

20. Mross K, Frost A, Steinbild S, Hedbom S, Büchert M, Fasol U, Unger C, Krätzschmar J, Heinig R, Boix O, Christensen O: A phase I dose-escalation study of regorafenib (BAY 73-4506), an inhibitor of oncogenic, angiogenic, and stromal kinases, in patients with advanced solid tumors. Clin Cancer Res 2012, 18(9):2658-67.

21. George S, Wang Q, Heinrich MC, Corless CL, Zhu M, Butrynski JE, Morgan JA, Wagner AJ, Choy E, Tap WD, Yap JT, Van den Abbeele AD, Manola JB, Solomon SM, Fletcher JA, von Mehren M, Demetri GD: Efficacy and safety of regorafenib in patients with metastatic and/or unresectable GI stromal tumor after failure of imatinib and sunitinib: a multicenter phase II trial. J Clin Oncol 2012, 30(19):2401-7.
22. Demetri GD, Reichardt P, Kang YK, Blay JY, Rutkowski P, Gelderblom H, Hohenberger $\mathrm{P}$, Leahy $\mathrm{M}$, von Mehren $\mathrm{M}$, Joensuu $\mathrm{H}$, Badalamenti $\mathrm{G}$, Blackstein M, Le Cesne A, Schöffski P, Maki RG, Bauer S, Nguyen BB, Xu J, Nishida T, Chung J, Kappeler C, Kuss I, Laurent D, Casali PG, GRID study investigators: Efficacy and safety of regorafenib for advanced gastrointestinal stromal tumours after failure of imatinib and sunitinib (GRID): an international, multicentre, randomised, placebo-controlled, phase 3 trial. Lancet 2013, 381(9863):295-302.

23. Eisenhauer EA, Therasse P, Bogaerts J, Schwartz LH, Sargent D, Ford R, Dancey J, Arbuck S, Gwyther S, Mooney M, Rubinstein L, Shankar L, Dodd L, Kaplan R, Lacombe D, Verweij J: New response evaluation criteria in solid tumours: revised RECIST guideline (version 1.1). Eur J Cancer 2009, 45(2):228-47.

24. Choi H, Charnsangavej C, Faria SC, Macapinlac HA, Burgess MA, Patel SR, Chen LL, Podoloff DA, Benjamin RS: Correlation of computed tomography and positron emission tomography in patients with metastatic gastrointestinal stromal tumor treated at a single institution with imatinib mesylate: proposal of new computed tomography response criteria. J Clin Oncol 2007, 25(13):1753-9.

25. Shinagare $A B$, Jagannathan JP, Kurra V, Urban T, Manola J, Choy E, Demetri GD, George S, Ramaiya NH: Comparison of performance of various tumour response criteria in assessment of regorafenib activity in advanced gastrointestinal stromal tumours after failure of imatinib and sunitinib. Eur J Cancer 2014, 50(5):981-6.

26. Strumberg D, Scheulen ME, Schultheis B, Richly H, Frost A, Büchert M, Christensen O, Jeffers M, Heinig R, Boix O, Mross K: Regorafenib (BAY 734506) in advanced colorectal cancer: a phase I study. Br J Cancer 2012, 106(11):1722-7.

27. Eisen $T$, Joensuu $H$, Nathan PD, Harper PG, Wojtukiewicz MZ, Nicholson S, Bahl A, Tomczak P, Pyrhonen S, Fife K, Bono P, Boxall J, Wagner A, Jeffers M, Lin T, Quinn DI: Regorafenib for patients with previously untreated metastatic or unresectable renal-cell carcinoma: a single-group phase 2 trial. Lancet Oncol 2012, 13(10):1055-62.

28. Grothey A, Van Cutsem E, Sobrero A, Siena S, Falcone A, Ychou M, Humblet Y, Bouché O, Mineur L, Barone C, Adenis A, Tabernero J, Yoshino T, Lenz HJ, Goldberg RM, Sargent DJ, Cihon F, Cupit L, Wagner A, Laurent D, CORRECT Study Group: Regorafenib monotherapy for previously treated metastatic colorectal cancer (CORRECT): an international, multicentre, randomised, placebo-controlled, phase 3 trial. Lancet 2013, 381(9863):303-12.

29. Grothey A, George S, van Cutsem E, Blay JY, Sobrero A, Demetri GD: Optimizing treatment outcomes with regorafenib: personalized dosing and other strategies to support patient care. Oncologist 2014, 19(6):669-80.

30. Poole CD, Connolly MP, Chang J, Currie CJ: Health utility of patients with advanced gastrointestinal stromal tumors (GIST) after failure of imatinib and sunitinib: findings from GRID, a randomized, double-blind, placebo-controlled phase III study of regorafenib versus placebo. Gastric Cancer; 2014. Jun 24 [Epub ahead of print].

doi:10.1186/2045-3329-4-17

Cite this article as: Kollàr et al:: Regorafenib treatment for advanced, refractory gastrointestinal stromal tumor: a report of the UK managed access program. Clinical Sarcoma Research 2014 4:17

\section{Submit your next manuscript to BioMed Central and take full advantage of:}

- Convenient online submission

- Thorough peer review

- No space constraints or color figure charges

- Immediate publication on acceptance

- Inclusion in PubMed, CAS, Scopus and Google Scholar

- Research which is freely available for redistribution 